\title{
Identification of novel mutations in RNA-dependent RNA polymerases of SARS-CoV-2 and their implications on its protein structure
}

\author{
Gyanendra Bahadur Chand $^{1}$, Atanu Banerjee ${ }^{2}$, Gajendra Kumar Azad $^{\text {Corresp. } 1}$ \\ 1 Department of Zoology, Patna University, Patna, Bihar, India \\ 2 Department of Zoology, Samastipur College, Samastipur, Bihar, India \\ Corresponding Author: Gajendra Kumar Azad \\ Email address: gkazadpatnauniversity@gmail.com
}

The rapid development of SARS-CoV-2 mediated COVID-19 pandemic has been the cause of significant health concern, highlighting the immediate need for the effective antivirals. SARS-CoV-2 is an RNA virus that has an inherent high mutation rate. These mutations drive viral evolution and genome variability, thereby, facilitating viruses to have rapid antigenic shifting to evade host immunity and to develop drug resistance. Viral RNAdependent RNA polymerases (RdRp) perform viral genome duplication and RNA synthesis. Therefore, we compared the available RdRp sequences of SARS-CoV-2 from Indian isolates and 'Wuhan wet sea food market virus' sequence to identify, if any, variation between them. Our data revealed the occurrence of seven mutations in Indian isolates of SARSCoV-2. The secondary structure prediction analysis of these seven mutations shows that three of them cause alteration in the structure of RdRp. Furthermore, we did protein modelling studies to show that these mutations can potentially alter the stability of RdRp protein. Therefore, we propose that RdRp mutations in Indian SARS-CoV-2 isolates might have functional consequences that can interfere with RdRp targeting pharmacological agents. 
1 Identification of novel mutations in RNA-dependent RNA polymerases of

2 SARS-CoV-2 and their implications on its protein structure

3

4 Gyanendra Bahadur Chand ${ }^{1}$, Atanu Banerjee ${ }^{2}$ and Gajendra Kumar Azad ${ }^{3 \#}$

5

6 'Department of Zoology, Patna University, Patna-800005, Bihar, India

7 2Department of Zoology, Samastipur College, Samastipur-848134, Bihar, India

8 'Department of Zoology, Patna University, Patna-800005, Bihar, India

\#Corresponding Author:

11

Gajendra Azad

12

Email address: gkazad@patnauniversity.ac.in

14

Keywords: COVID-19, SARS-CoV-2, RNA-dependent RNA polymerases (RdRp), Nsp12, Mutation, Indian geographical area 
62 Chaplin, 2010; Jensen \& Thomsen, 2012). Being an efficient unique pathogen, a virus, 63 often mutate its proteins in a manner that it can still infect the host cells, evading the host's immune system. Even when fruitful strategies are discovered and engaged, the high rate of genetic change displayed by viruses frequently leads to drug resistance or vaccine escape (McKeegan, Borges-Walmsley \& Walmsley, 2002).

The SARS-CoV-2 has a single stranded RNA genome of approximately $29.8 \mathrm{~Kb}$ in length and accommodates 14 ORFs encoding 29 proteins that includes four structural proteins: Envelope (E), Membrane (M), Nucleocapsid (N) and Spike (S) proteins, 16 non-structural proteins (nsp) and 9 accessory proteins (Gordon et al., 2020a).(Wu et al., 2020 ) including the RNA dependent RNA polymerase (RdRp) (also named as nsp12). $\mathrm{RdRp}$ is comprised of multiple distinct domains that catalyze RNA-template dependent synthesis of phosphodiester bonds between ribonucleotides. The SARS-CoV-2 RdRp is the prime constituent of the replication/transcription machinery. The structure of the SARS-CoV-2 RdRp has recently been solved (Gao et al., 2020) and show three distinct domains.

For RNA viruses, the RNA-dependent RNA polymerase (RdRp) presents an ideal target because of its vital role in RNA synthesis and absence of host homolog. RdRp is therefore, a primary target for antiviral inhibitors such as Remdesivir (Gordon et al., $2020 \mathrm{~b}$ ) that is being considered as a potential drug for the treatment of COVID-19. Since, RNA viruses constantly evolve owing to the rapid rate of mutations in their genome, we decided to analyse RdRp protein sequence of SARS-CoV-2 from different geographical region to see if RdRp also mutate. Here, in the present study, we identified and characterised three mutations in RdRp protein isolated from India against that of the 'Wuhan wet sea food market' (Wu et al., 2020) SARS-CoV-2. Altogether, our data strongly suggests the prevalence of mutations in the genome of SARS-CoV-2 needs to be considered to develop new approaches for targeting this virus.

\section{METHODS}

Sequence retrieval:

We downloaded all SARS-CoV2 sequences from the NCBI virus database as shown in table 1 . As of now, there are 28 SARS-CoV-2 sequences from India have been 
deposited in this database, out of which, two sequences are not complete; therefore, we retrieved 26 datasets of SARS-CoV-2 (samples are from Indian). As a reference, we downloaded the sequence of SARS-CoV-2 that was first reported genome sequence deposited in the NCBI virus database from the 'Wuhan wet sea food market area' from the early days of COVID-19 pandemic (Wu et al., 2020). This virus was formerly called 'Wuhan seafood market pneumonia virus having the accession number YP_009724389.

Sequence alignments and structure:

All the RdRp protein sequences were aligned by multiple sequence alignment platform of CLUSTAL Omega (Madeira et al., 2019). Clustal Omega is a multiple sequence alignment program that uses seeded guide trees and HMM profile-profile techniques to generate alignments between three or more sequences. The alignment file was carefully studied and differences in the amino acid changes were recorded.

Secondary structure predictions:

We used CFSSP (Ashok Kumar, 2013) (Chou and Fasman secondary structure prediction), an online server, to predict secondary structures of SARS-CoV-2 RdRp protein. This server predicts the possibility of secondary structure such as alpha helix, beta sheet, and turns from the amino acid sequence. CFSSP uses Chou-Fasman algorithm, which is based on analyses of the relative frequencies of each amino acid in secondary structures of proteins solved with X-ray crystallography.

RdRp dynamics study:

To investigate the effect of mutation on the RdRp protein structural conformation, its molecular stability and flexibility, we used DynaMut software (Rodrigues, Pires \& Ascher, 2018) (University of Melbourne, Australia). To run this software we first downloaded the known protein structure of SARS-CoV-2 RdRp from RCSB (PDB ID: 6M71(Gao et al., 2020), 7BV1 and 7BV2(Yin et al., 2020) and used it for analysis. Next, the 6M71,7BV1 and 7BV2 structure was uploaded on DynaMut software and effect of mutation in various protein structure stability parameters such as vibrational entropy; the atomic fluctuations and deformation energies were determined. DynaMut, a web server 
124 implements well established normal mode approaches that is used to analyse and

125 visualise protein dynamics. This software samples conformations and measures the 126 impact of mutations on protein dynamics and stability resulting from vibrational entropy

127 changes and also predicts the impact of a mutation on protein stability.

128

129

130

131

132

133

134

135

136

137

138

139

140

141

142

143

144

145

146

147

148

149

150

151

152

153

154

RESULTS:

Identification of mutations in RdRp protein present in Indian isolates

The SARS-COV-2 sequencing data was downloaded from NCBI (NCBI-Virus-SARSCoV-2 data hub). There are 26 SARS-CoV-2 sequences available from India. We downloaded all Indian SARS-CoV-2 sequences and Wuhan SARS-CoV-2 sequence, which was deposited for the first time after COVID-19 cases started to appear in Wuhan province, China. We downloaded protein sequence of NSP12/ RdRp from the database. All these RdRp sequences were first aligned in CLUSTAL Omega to check for similarities or differences. The Clustal Omega algorithm produces a multiple sequence alignment by producing pairwise alignments. Using this algorithm, we identified seven mutations in isolates from Indian SARS-CoV-2 samples compared to Wuhan SARSCoV-2 RdRp sequence as shown in figure 1. We considered the original Wuhan sequence as the wild type for this comparison. These mutations on RdRp are A97V, A185V, I201L, P323L, L329I, A466V and V880I respectively. Out of these, one isolate have triple mutation, two isolates have double mutation, and rest have single mutations (figure 1).

P323L mutation causes the alteration in secondary structure of RdRp Next, we studied the effect of these mutations on secondary structure of RdRp. Our data revealed that mutation at four positions have no effect in secondary structure that includes I201L, L329I, A466V and V880I (figure 2 C, E, F and G). However, mutation in rest of the three sites causes change in secondary structure (A97V, A185V and P323L) as shown in figure 2 (panel A, B and D). At two positions (97 and 185) the alanine amino acid is substituted by valine. The valine side chain is larger than alanine, and substitution of valine at position 97 and 185 impairs packing of the protein as revealed by our secondary structure predications at these two sites (figure $2 \mathrm{~A}$ and $2 \mathrm{~B}$, compare 
155 panel $\mathrm{i}$ and ii). Our analysis showed that there is addition of two sheet at positions 97

156 and 98 due to mutation of A97V (figure 2A, compare panel i and ii). Similarly, in A185V

157 mutant, there is a loss of turn at 184 and replacement of helix with sheet structure at

158 181, 182, 183 and 184 positions (figure 2B, compare panel $i$ and ii). Further, our

159 secondary structure prediction also showed changes in secondary structure when

160 proline is substituted by leucine at 323 position (Figure 2D and $\mathrm{H}$, compare panel $\mathrm{i}$ and

161 ii). The detailed analysis revealed that the mutant $\operatorname{RdRp}(\mathrm{P} 323 \mathrm{~L})$ have attained

162 considerable changes in secondary structure at the mutation site. There is a loss of turn

163 structures from position 323 and 324 and addition of five sheets at positions 321, 322,

164323,324 and 327 (Figure 2D and H, highlighted in dashed box). Proline possesses a

165 unique property, its side chain cyclizes back on to the backbone amide position, due to

166 which it contributes to the secondary structure formation because of its bulky pyrrolidine

167 ring that places steric constraints on the conformation of the preceding residue in the

168 helix. The substitution of proline to leucine in the mutant RdRp might result in loss of the

169 structural integrity provided by proline. Leucine is a hydrophobic amino acid and

170 generally buried in the folded protein structure. Altogether, the substitution of alanine to

171 valine at position 97, 185 and proline to leucine at position 323 in mutant $R d R p$ is

172 changing the secondary structure of the protein that might have functional

173 consequences.

174

$175 P 323 L$ alters the stability dynamics of tertiary structure of RdRp.

176 To understand the impact of mutations on tertiary structure of RdRp, we performed

177 protein modelling using Dynamut software (Rodrigues, Pires \& Ascher, 2018). The

178 Dynamut software provide us the information about the alteration in protein stability and

179 flexibility due to the mutations in the native protein structure. Our data revealed that

180 there is change in vibrational entropy energy $\left(\Delta \Delta \mathrm{S}_{\mathrm{Vib}} \mathrm{ENCoM}\right)$ between the wild type

181 (Wuhan isolate) and the mutant Indian isolate (Figure 3A). Vibrational entropy

182 represents an average of the configurational entropies of the protein within single

183 minima of the energy landscape (Goethe, Fita \& Rubi, 2015). The negative

$184 \Delta \Delta S_{\mathrm{Vib}} \mathrm{ENCoM}$ of mutant $\mathrm{RdRp}$ represents the rigidification of the protein structure and 185 positive $\Delta \Delta \mathrm{S}_{\mathrm{Vib}} \mathrm{ENCoM}$ represents gain in flexibility. Here, our data show that the 
186 mutation at $\mathrm{A} 185 \mathrm{~V}$ and $\mathrm{P} 323 \mathrm{~L}$ lead to rigidification of mutant protein structure Figure 3B

187 and D). However, the mutation at I201L leads to increase in flexibility (Figure 3C).

188 Further, we also calculated the free energy differences, $\Delta \Delta G$, between wild-type and

189 mutant. The free energy differences, $\Delta \Delta G$, caused by mutation have been correlated

190 with the structural changes, such as changes in packing density, cavity volume and

191 accessible surface area and therefore, it measures effect of mutation on protein

192 stability(Eriksson et al., 1992). In general, a $\Delta \Delta G$ below zero means that the mutation

193 causes destabilization and above zero represents protein stabilization. Here, our

194 analysis showed positive $\Delta \triangle G$ for $\mathrm{A} 185 \mathrm{~V}$ and $\mathrm{P} 323 \mathrm{~L}$ mutations suggesting that $\mathrm{P} 323 \mathrm{~L}$

195 mutation is stabilising protein structure (Figure 3A); however, we observed negative

$196 \Delta \Delta G$ for I201L mutation indicating its destabilising behaviour (Figure $3 \mathrm{~A}$ ). The $\Delta \Delta G$ for

$197 \mathrm{P} 323 \mathrm{~L}$ mutant was $0.908 \mathrm{kcal} / \mathrm{mol}$ which is significantly higher than others. Therefore,

198 we also did protein modelling of P323L mutant using two additional structures of RdRp

199 (7BV1, 7BV2)(Yin et al., 2020) and analysed its impact on $\Delta \Delta G$. Our data show that in

200 both the cases (7BV1 and 7BV2) the P323L mutation is leading to stabilisation of the

201 protein structure with the values of $\Delta \Delta \mathrm{G}$ as $0.530 \mathrm{kcal} / \mathrm{mol}$ and $0.460 \mathrm{kcal} / \mathrm{mol}$

202 respectively.

203 We further closely analysed the changes in the intramolecular interactions due to these

204 three mutations in RdRp. Our data showed that it is affecting the interactions of the

205 residues which are present in the close vicinity of alanine, isoleucine and proline. The

206 substitution of wild type residues with mutant residues alters the side chain leading to

207 change of intramolecular bonds in the pocket, where these amino acids resides as

208 shown in figure $4 \mathrm{~A}, \mathrm{~B}$ and $\mathrm{C}$. Therefore, it can be conclusively stated that the three

209 mutations namely, A97V, A185V and P323L, in large, are changing the stability and

210 intramolecular interactions in the protein that might have functional consequences.

211

\section{DISCUSSION}

213 RNA viruses including coronaviruses exhibits high mutation rates that provide these

214 viruses evolutionary advantage to better adapt and survivability (Domingo \& Holland,

215 1997). Mutations derive the process of natural selection by selecting those viral strains

216 that are more potent and fit (Duffy, 2018) that facilitates drug resistance and immune 
217 evasions (Irwin et al., 2016). The SARS-CoV-2 infected humans from Wuhan province

218 in China and quickly spread to almost all countries worldwide. Since, this virus has

219 already spread to different demographic areas having different climatic condition,

220 temperature, humidity and seasonal variations; therefore, we can predict that this virus

221 might be mutating to adapt to new environments. Towards this, we investigated the

222 mutations in RdRp of SARS-CoV-2. We focused primarily on RdRp because it is an

223 indispensable protein of this virus that helps in its replication and transcription. More

224 importantly, there are many drugs which specifically target RdRp and are potent

225 antivirals. Our study reports the RdRp mutations present in the Indian isolates of SARS-

226 CoV-2 and, will help to understand the effect of variations on RdRp protein. Our data

227 demonstrate that $\mathrm{A} 97 \mathrm{~V}, \mathrm{~A} 185 \mathrm{~V}$ and P323Lmutations lead to significant changes in the

228 protein secondary structure (Figure 2). P323L mutation lies in the interface domain

229 (residues A250-R365) of the RdRp protein. This domain helps in the coordination of $\mathrm{N}$

230 and $\mathrm{C}$ terminal domains of $\mathrm{RdRp}$; therefore, a mutation in the interface domain might

231 have drastic impact on the function of RdRp. A recent virtual molecular docking studies,

232 screened approximately 7500 drugs to identify SARS-CoV-2 RdRp inhibitor revealed

233 several potential compounds (DOI: 10.20944/preprints202003.0024.v1) namely,

234 Simeprevir, Filibuvir and Tegobuvir, etc. Same study also predicted that these drugs

235 bind RdRp at a putative docking site (a hydrophobic cleft) that includes phenylalanine at

$236326^{\text {th }}$ position. Interestingly, the mutation identified in our study is very close to the

237 docking site (P323L and L329I). Therefore, it is reasonable that the substitution of these

238 two amino acids at 323 and 329 might interfere with the interaction of these drugs with

239 RdRp. Further, our data also revealed that P323L mutation is causing stabilisation of

240 the protein structure. The mutations in RdRp have already been linked to drug

241 resistance in different viruses. Such as a study on RdRp of influenza A virus

242 demonstrate that a K229R mutation confers resistance to favipiravir (Goldhill et al.,

243 2018). Similarly, mutation in hepatitis C virus RdRp at P495, P496 or V499 \& T389 and

244 have been linked to drug resistance (Delang et al., 2012). Altogether, it is conceivable

245 that many RNA viruses acquire drug resistance through mutations in RdRp. However,

246 the functional characterisation of RdRp mutations investigated in our study needs to be 
247 carried out to understand the exact role of these mutations which will help scientific

248 community to better therapeutic targeting of SARS-CoV-2.

249

250

CONCLUSIONS

251 Altogether, our data strongly suggests that SARS-CoV-2 is acquiring mutations as it is spreading to new locations. Most likely, these mutations are helping SARS-CoV-2 to adapt better inside host and new geographical locations. One of the mutations identified in our study (P323L) might have functional consequences that need to be addressed in future studies.

256

257

258

ACKNOWLEDGEMENTS

We would like to thank Patna University, Patna for providing necessary infrastructural support.

261

FIGURE AND TABLE LEGENDS

Figure 1: Multiple sequence alignment of Wuhan SARS-CoV-2 RdRp protein with sequences obtained from India. The mutations are highlighted in red font. Only those sequences are shown that have variations, rest of the sequences are identical among all samples.

Figure 2: Effect of mutations on secondary structure of RdRp. Figure A, B, C, D, E, F, G and $\mathrm{H}$ demonstrate seven mutations observed in Indian isolates. Panel (i) represents sequence of Wuhan isolate and panel (ii) represents sequence of Indian isolates. The small rectangular box shows the mutant residue. The difference of secondary structure between Wuhan and Indian isolates are highlighted with dashed box in respective 273 panels.

Figure 3: Analysis of RdRp dynamicity and flexibility. A) The table shows the values of change in $\Delta \Delta S$ ENCoM and $\Delta \Delta G$ due to the mutation. B) $\Delta$ Vibrational Entropy Energy between Wild-Type and Mutant RdRp, amino acids are colored according to the 
278 vibrational entropy change as a consequence of mutation of RdRp

279 protein. BLUE represents a rigidification of the structure and RED a gain in flexibility.

280

281

282

283

284

285

286

287

288

289

290

291

292

293

294

295

296

297

298

299

300

301

302

303

304

305

306

307

308

Figure 4: Interatomic interactions mediated by A185V, I201L and P323L of RdRp- (A-B) represents alanine to valine substitution at $185^{\text {th }}$ position, (C-D) represents isoleucine to leucine substitution at $201^{\text {st }}$ position, (E-F) represents proline to leucine substitutions at $323^{\text {rd }}$ position. Wild-type and mutant residues are colored in light-green and are also represented as sticks alongside with the surrounding residues which are involved on any type of interactions.

Table 1: Details of SARS-CoV-2 sequences used in this study

\section{REFERENCES}

Alcami A, Koszinowski UH. 2000. Viral mechanisms of immune evasion. Trends in Microbiology. DOI: 10.1016/S0966-842X(00)01830-8.

Ashok Kumar T. 2013. CFSSP: Chou and Fasman Secondary Structure Prediction server. Wide Spectrum. DOI: 10.5281/zenodo.50733.

Chaplin DD. 2010. Overview of the immune response. Journal of Allergy and Clinical Immunology. DOI: 10.1016/j.jaci.2009.12.980.

Delang L, Froeyen M, Herdewijn P, Neyts J. 2012. Identification of a novel resistance mutation for benzimidazole inhibitors of the HCV RNA-dependent RNA polymerase. Antiviral Research. DOI: 10.1016/j.antiviral.2011.10.012.

Domingo E, Holland JJ. 1997. RNA VIRUS MUTATIONS AND FITNESS FOR SURVIVAL. Annual Review of Microbiology. DOI: 10.1146/annurev.micro.51.1.151.

Duffy S. 2018. Why are RNA virus mutation rates so damn high? PLoS Biology. DOI: 10.1371/journal.pbio.3000003.

Eriksson AE, Baase WA, Zhang XJ, Heinz DW, Blaber M, Baldwin EP, Matthews BW. 1992. Response of a protein structure to cavity-creating mutations and its relation to the hydrophobic effect. Science. DOI: 10.1126/science.1553543.

Gao Y, Yan L, Huang Y, Liu F, Zhao Y, Cao L, Wang T, Sun Q, Ming Z, Zhang L, Ge J, Zheng L, Zhang Y, Wang H, Zhu Y, Zhu C, Hu T, Hua T, Zhang B, Yang X, Li J, 
Yang H, Liu Z, Xu W, Guddat LW, Wang Q, Lou Z, Rao Z. 2020. Structure of the RNA-dependent RNA polymerase from COVID-19 virus. Science. DOI: 10.1126/science.abb7498.

Goethe M, Fita I, Rubi JM. 2015. Vibrational entropy of a protein: Large differences between distinct conformations. Journal of Chemical Theory and Computation. DOI: 10.1021/ct500696p.

Goldhill DH, Te Velthuis AJW, Fletcher RA, Langat P, Zambon M, Lackenby A, Barclay WS. 2018. The mechanism of resistance to favipiravir in influenza. Proceedings of the National Academy of Sciences of the United States of America. DOI: 10.1073/pnas. 1811345115.

Gordon DE, Jang GM, Bouhaddou M, Xu J, Obernier K, O\&\#039;Meara MJ, Guo JZ, Swaney DL, Tummino TA, Huttenhain R, Kaake RM, Richards AL, Tutuncuoglu B, Foussard H, Batra J, Haas K, Modak M, Kim M, Haas P, Polacco BJ, Braberg H, Fabius JM, Eckhardt M, Soucheray M, Bennett MJ, Cakir M, McGregor MJ, Li Q, Naing ZZC, Zhou Y, Peng S, Kirby IT, Melnyk JE, Chorba JS, Lou K, Dai SA, Shen W, Shi Y, Zhang Z, Barrio-Hernandez I, Memon D, Hernandez-Armenta C, Mathy CJP, Perica T, Pilla KB, Ganesan SJ, Saltzberg DJ, Ramachandran R, Liu X, Rosenthal SB, Calviello L, Venkataramanan S, Liboy-Lugo J, Lin Y, Wankowicz SA, Bohn M, Sharp PP, Trenker R, Young JM, Cavero DA, Hiatt J, Roth T, Rathore U, Subramanian A, Noack J, Hubert M, Roesch F, Vallet T, Meyer B, White KM, Miorin L, Rosenberg OS, Verba KA, Agard D, Ott M, Emerman M, Ruggero D, Garc\&amp;amp;iacute-Sastre A, Jura N, von Zastrow M, Taunton J, Ashworth A, Schwartz O, Vignuzzi M, d\&\#039;Enfert C, Mukherjee S, Jacobson M, Malik HS, Fujimori DG, Ideker T, Craik CS, Floor S, Fraser JS, Gross J, Sali A, Kortemme T, Beltrao P, Shokat K, Shoichet BK, Krogan NJ. 2020a. A SARS-CoV-2-Human Protein-Protein Interaction Map Reveals Drug Targets and Potential DrugRepurposing. bioRxiv. DOI: 10.1101/2020.03.22.002386.

Gordon CJ, Tchesnokov EP, Woolner E, Perry JK, Feng JY, Porter DP, Gotte M. 2020b. Remdesivir is a direct-acting antiviral that inhibits RNA-dependent RNA polymerase from severe acute respiratory syndrome coronavirus 2 with high potency. Journal of Biological Chemistry. DOI: 10.1074/jbc.ra120.013679. 
340 Irwin KK, Renzette N, Kowalik TF, Jensen JD. 2016. Antiviral drug resistance as an 341 adaptive process. Virus Evolution. DOI: 10.1093/ve/vew014.

342 Jensen S, Thomsen AR. 2012. Sensing of RNA Viruses: a Review of Innate Immune 343 Receptors Involved in Recognizing RNA Virus Invasion. Journal of Virology. DOI: $344 \quad$ 10.1128/jvi.05738-11.

Madeira F, Park YM, Lee J, Buso N, Gur T, Madhusoodanan N, Basutkar P, Tivey ARN,

Rodrigues CHM, Pires DEV, Ascher DB. 2018. DynaMut: Predicting the impact of mutations on protein conformation, flexibility and stability. Nucleic Acids Research. DOI: $10.1093 /$ nar/gky300.

Sackman AM, McGee LW, Morrison AJ, Pierce J, Anisman J, Hamilton H, Sanderbeck S, Newman C, Rokyta DR. 2017. Mutation-driven parallel evolution during viral adaptation. Molecular Biology and Evolution. DOI: 10.1093/molbev/msx257.

Wu F, Zhao S, Yu B, Chen YM, Wang W, Song ZG, Hu Y, Tao ZW, Tian JH, Pei YY, Yuan ML, Zhang YL, Dai FH, Liu Y, Wang QM, Zheng JJ, Xu L, Holmes EC, Zhang YZ. 2020. A new coronavirus associated with human respiratory disease in China. Nature. DOI: 10.1038/s41586-020-2008-3. 
Figure 1

Multiple sequence alignment of SARS-CoV-2 RdRp protein

Multiple sequence alignment of Wuhan SARS-CoV-2 RdRp protein with sequences obtained from India. The mutations are highlighted in red font. Only those sequences are shown that have variations, rest of the sequences are identical among all samples.

RdRp amino acid Sequence

\begin{tabular}{|c|c|c|c|c|c|c|c|c|}
\hline & Amino Acid Position & 97 & 185 & 201 & 323 & 329 & 406 & 880 \\
\hline \multirow{11}{*}{$\begin{array}{l}\text { Wuhan SARS-CoV-2 } \longrightarrow \\
\text { (Accession No) }\end{array}$} & YP_009724389 & A & A & 1 & $\mathrm{P}$ & L & A & V \\
\hline & QJQ28343 & A & A & 1 & $L$ & $\mathrm{~L}$ & A & V \\
\hline & QJQ28427 & A & $A$ & 1 & $L$ & $I$ & A & V \\
\hline & QJQ28355 & A & $v$ & $L$ & $L$ & $\mathrm{~L}$ & A & V \\
\hline & QJQ28415 & A & A & 1 & $L$ & L & A & 1 \\
\hline & QJQ28367 & A & $A$ & 1 & $L$ & L & A & V \\
\hline & QJF77868 & $v$ & $A$ & 1 & $\mathrm{P}$ & L & A & V \\
\hline & QJC19489 & A & A & I & $L$ & L & A & V \\
\hline & QJF77856 & A & A & 1 & $L$ & L & A & V \\
\hline & QJF77880 & A & A & 1 & $L$ & L & A & V \\
\hline & QJQ28379 & A & A & 1 & $L$ & L & A & V \\
\hline \multirow{16}{*}{$\begin{array}{c}\text { Indian } \\
\text { SARS-CoV-2 } \\
\text { Isolate } \\
\text { (Accession No) }\end{array}$} & QJQ28391 & A & A & 1 & $L$ & L & A & V \\
\hline & QJQ28403 & A & A & 1 & $L$ & L & A & V \\
\hline & QIA98582 & A & A & 1 & $P$ & L & A & V \\
\hline & QJF77844 & A & A & 1 & $P$ & L & A & V \\
\hline & QHS34545 & A & A & 1 & $\mathrm{P}$ & L & $v$ & V \\
\hline & QJF11810 & A & A & 1 & $L$ & L & A & V \\
\hline & QJF11822 & A & A & 1 & $L$ & L & A & V \\
\hline & QJF11870 & A & A & 1 & $L$ & L & A & V \\
\hline & QJQ27852 & A & A & 1 & $L$ & L & A & V \\
\hline & QJF11858 & $V$ & A & 1 & $\mathrm{P}$ & L & A & V \\
\hline & QJF11882 & $V$ & A & 1 & P & L & A & V \\
\hline & QJQ27840 & $V$ & A & 1 & $P$ & L & A & V \\
\hline & QJQ27876 & $V$ & A & 1 & P & L & A & V \\
\hline & QJF11834 & $V$ & A & 1 & P & L & A & V \\
\hline & QJF11846 & $v$ & A & I & P & L & A & V \\
\hline & QJQ27864 & $v$ & A & 1 & $\mathrm{P}$ & $\mathrm{L}$ & A & V \\
\hline
\end{tabular}


Figure 2

Prediction of secondary structure of RdRp protein

Effect of mutations on secondary structure of RdRp. Figure $A, B, C, D, E, F, G$ and $H$

demonstrate seven mutations observed in Indian isolates. Panel (i) represents sequence of

Wuhan isolate and panel (ii) represents sequence of Indian isolates. The small rectangular

box shows the mutant residue. The difference of secondary structure between Wuhan and

Indian isolates are highlighted with dashed box in respective panels.

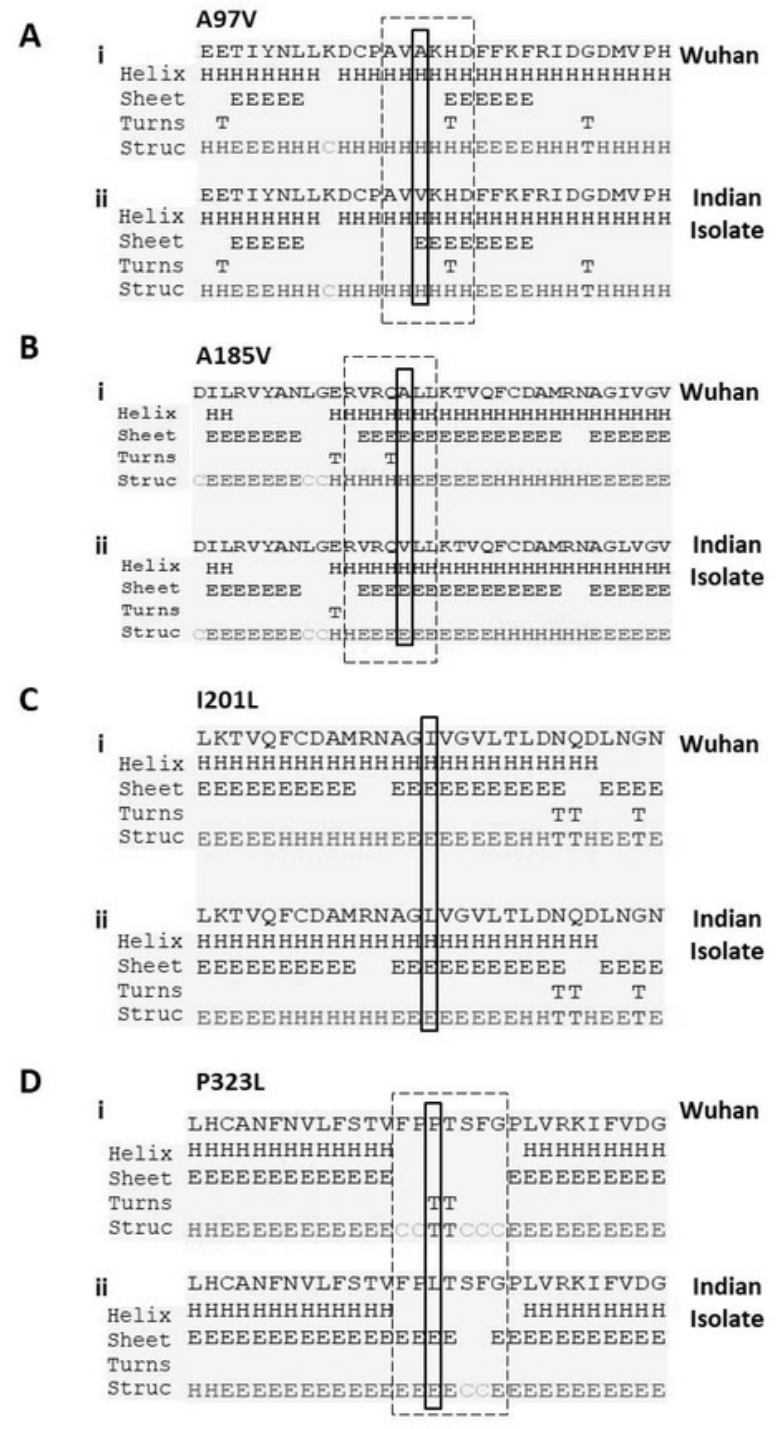

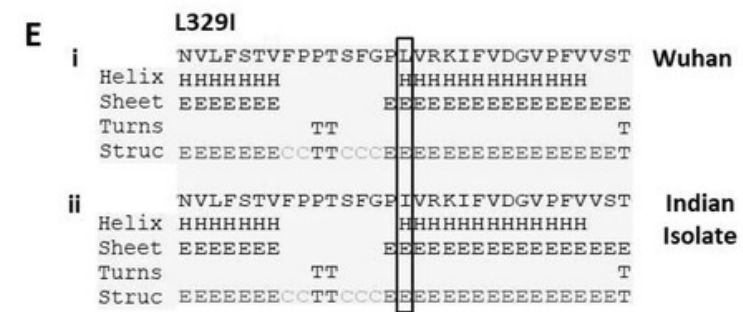
F A406V
i KRTTCFSVAALTNNYAFTVKRGNFNKDFY Wuhan Helix ннннннннннннннанннн
Sheet EEEEEEEEEEEE耳EE

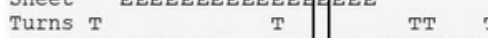
Struc THEEEEHHHEEEEEA
ii KRTTCFSVAALTNNYV FOTVKPGNFNKDFY

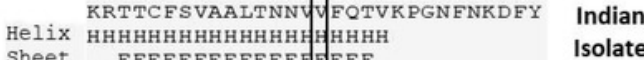

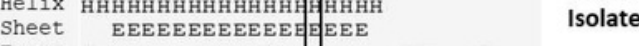
$\begin{array}{ll}\text { Turns } & T \\ \text { Struc } & \text { THEEEEHHHEEEEEHEEEHCTTCCCT }\end{array}$

G

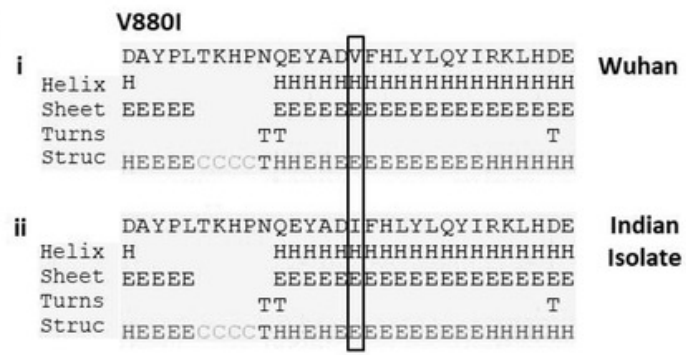

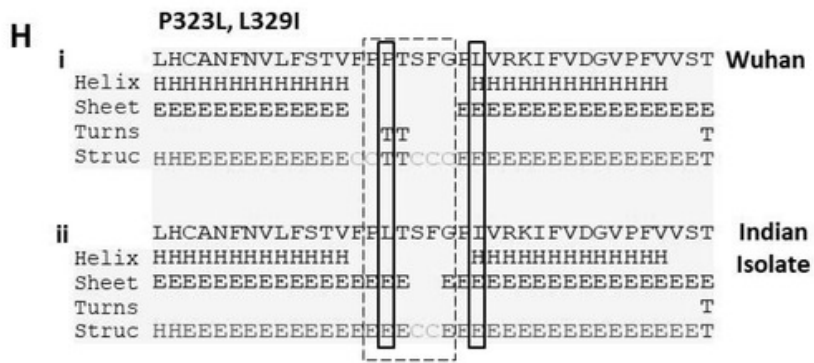


Figure 3

Effect of mutations on structural dynamics of RdRp protein

Analysis of RdRp dynamicity and flexibility. A) The table shows the values of change in $\Delta \Delta S$

ENCoM and $\Delta \Delta \mathrm{G}$ due to the mutation. B) $\Delta$ Vibrational Entropy Energy between Wild-Type and Mutant RdRp, amino acids are colored according to the vibrational entropy change as a consequence of mutation of RdRp protein. BLUErepresents a rigidification of the structure and REDa gain in flexibility.

A

\begin{tabular}{|l|l|l|l|l|l|}
\hline S. No & $\begin{array}{l}\text { Wuhan } \\
\text { Isolate }\end{array}$ & $\begin{array}{l}\text { Indian } \\
\text { Isolate }\end{array}$ & $\begin{array}{l}\text { Amino-acid } \\
\text { Position }\end{array}$ & $\Delta \Delta$ S ENCoM & $\Delta \Delta$ G DynaMut \\
\hline 1 & A & V & 185 & $-0.42 \mathrm{kcal} \cdot \mathrm{mol}^{-1} \cdot \mathrm{K}^{-1}$ & $0.134 \mathrm{kcal} / \mathrm{mol}$ \\
\hline 2 & I & L & 201 & $0.066 \mathrm{kcal} \cdot \mathrm{mol}^{-1} \cdot \mathrm{K}^{-1}$ & $-0.047 \mathrm{kcal} / \mathrm{mol}$ \\
\hline 3 & $\mathrm{P}$ & $\mathrm{L}$ & 323 & $-0.277 \mathrm{kcal} \cdot \mathrm{mol}^{-1} \cdot \mathrm{K}^{-1}$ & $0.908 \mathrm{kcal} / \mathrm{mol}$ \\
\hline
\end{tabular}
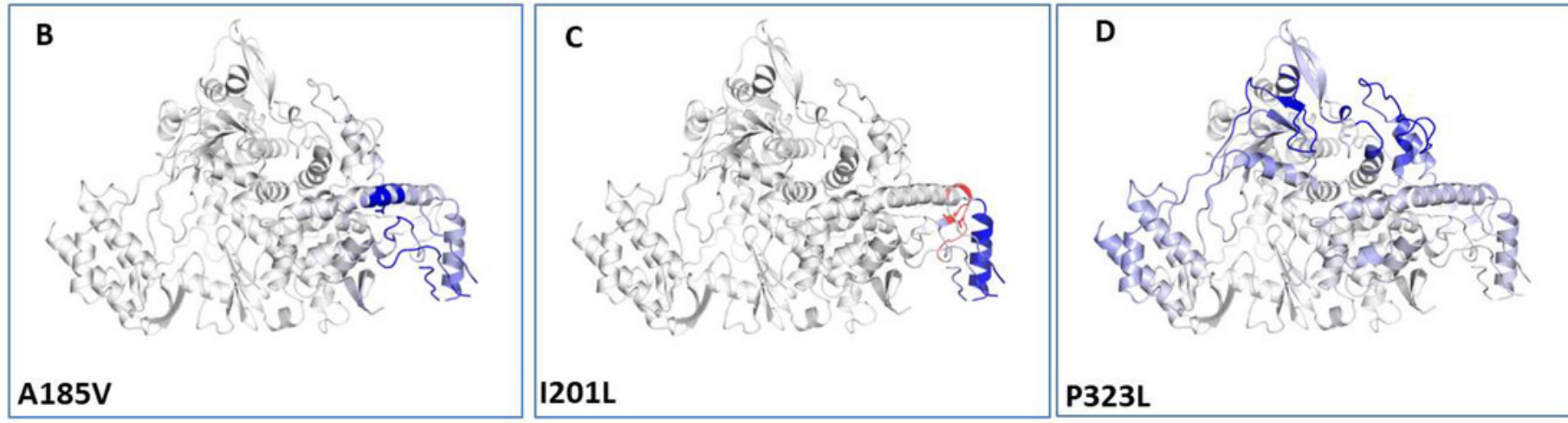


\section{Figure 4}

Effect of amino acid substitution on interatomic interactions

Interatomic interactions mediated by A185V, 1201L and P323L of RdRp- (A-B) represents alanine to valine substitution at $185^{\text {th }}$ position, (C-D) represents isoleucine to leucine substitution at $201^{\text {st }}$ position, (E-F) represents proline to leucine substitutions at $323^{\text {rd }}$ position. Wild-type and mutant residues are colored inlight-greenand are also represented as sticks alongside with the surrounding residues which are involved on any type of interactions. 


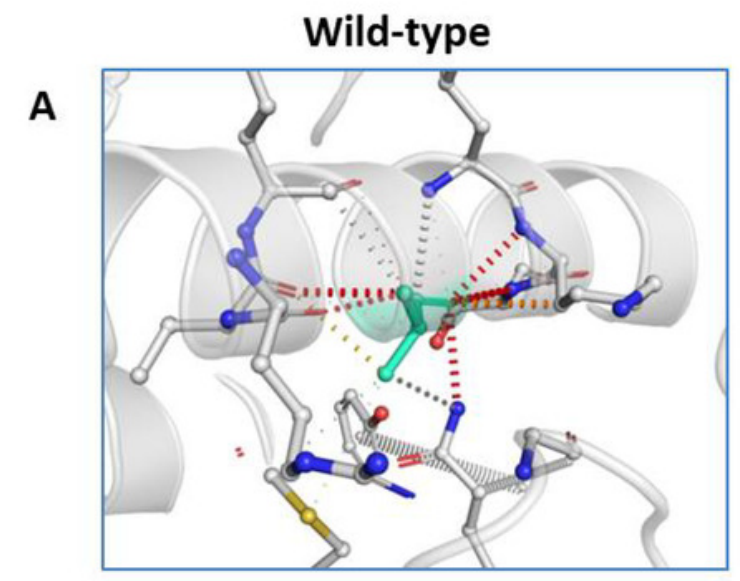

C

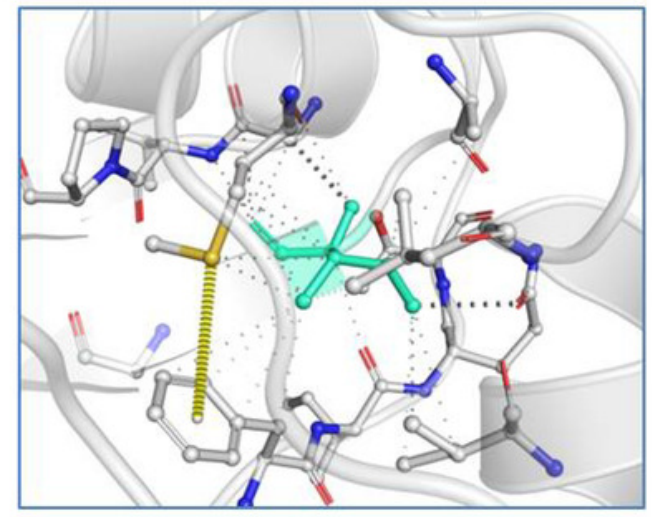

E

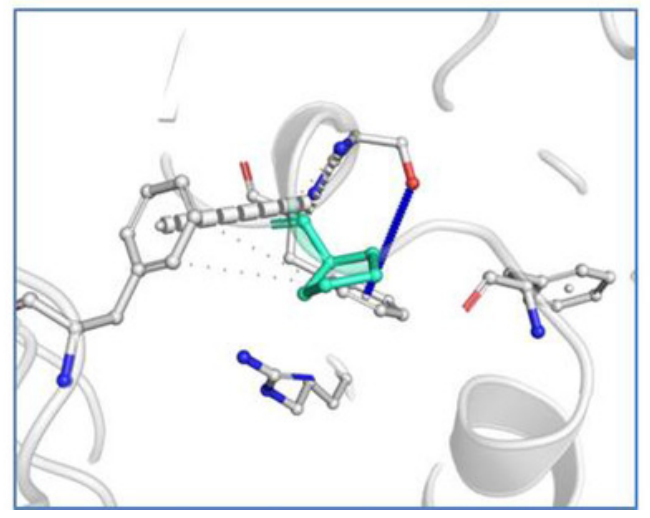

B

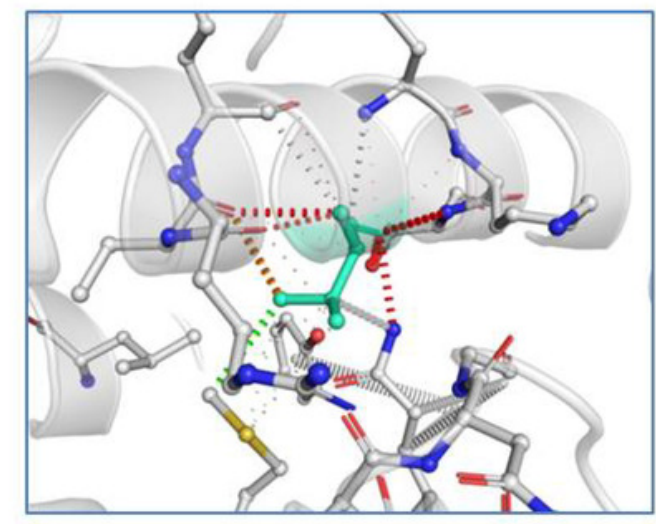

\section{Mutant}

D

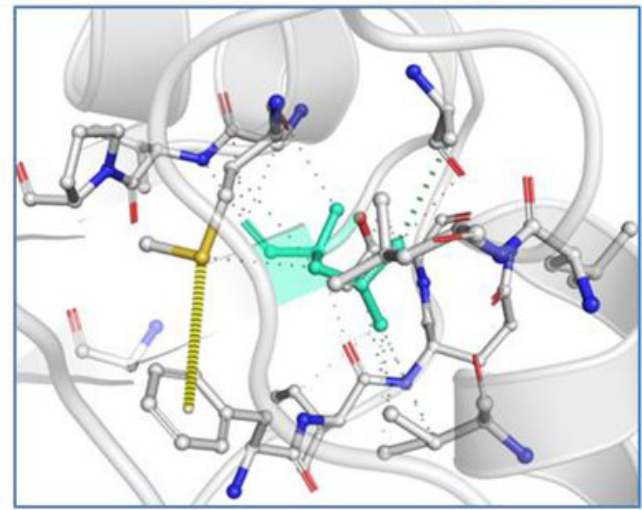

$\mathbf{F}$

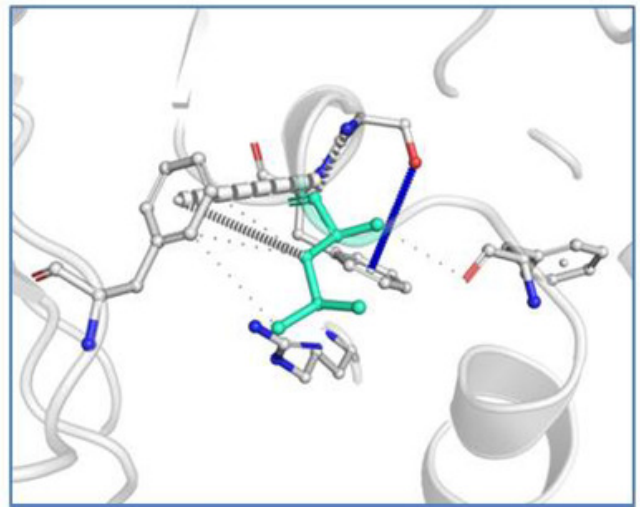

RdRp A185V

RdRp I201L

RdRp P323L 


\section{Table $\mathbf{1}$ (on next page)}

Details of SARS-CoV-2 sequences used in the analysis

The accession number of SARS-CoV-2 sequences used in this study are mentioned in the table. 
1 Table 1: Details of SARS-CoV-2 sequences used in the analysis

2

\begin{tabular}{|c|c|c|c|}
\hline S.No & $\begin{array}{l}\text { Accession } \\
\text { Number }\end{array}$ & Authors & Institute/ University \\
\hline 1 & YP_009724389 & Wu,F., Zhao,S., et al., 2020 & $\begin{array}{l}\text { Fudan University, Shanghai, } \\
\text { China }\end{array}$ \\
\hline 2 & QHS34545 & Yadav,P.D., et al., 2020 & $\begin{array}{l}\text { NIV, Pashan, Pune, } \\
\text { Maharashtra 411021, India }\end{array}$ \\
\hline 3 & QIA98582 & Potdar,V., et al., 2020 & $\begin{array}{l}\text { NIV, Pashan, Pune, } \\
\text { Maharashtra 411021, India }\end{array}$ \\
\hline 4 & QJC19489 & Pandit,R.,Shah,T., et al., 2020 & $\begin{array}{l}\text { GBRC, Gandhinagar, } \\
\text { Gujarat } 382010, \text { India }\end{array}$ \\
\hline 5 & QJF11810 & Pattabiraman,C., et al., 2020 & $\begin{array}{l}\text { NIMHANS, Bangalore, } \\
\text { Karnataka 560029,India }\end{array}$ \\
\hline 6 & QJF11822 & Pattabiraman,C., et al., 2020 & $\begin{array}{l}\text { NIMHANS, Bangalore, } \\
\text { Karnataka 560029,India }\end{array}$ \\
\hline 7 & QJF11834 & Pattabiraman,C., et al., 2020 & $\begin{array}{l}\text { NIMHANS, Bangalore, } \\
\text { Karnataka 560029,India }\end{array}$ \\
\hline 8 & QJF11846 & Pattabiraman,C., et al., 2020 & $\begin{array}{l}\text { NIMHANS, Bangalore, } \\
\text { Karnataka 560029,India }\end{array}$ \\
\hline 9 & QJF11858 & Pattabiraman,C., et al., 2020 & $\begin{array}{l}\text { NIMHANS, Bangalore, } \\
\text { Karnataka 560029,India }\end{array}$ \\
\hline 10 & QJF11870 & Pattabiraman,C., et al., 2020 & $\begin{array}{l}\text { NIMHANS, Bangalore, } \\
\text { Karnataka 560029,India }\end{array}$ \\
\hline 11 & QJF11882 & Pattabiraman,C., et al., 2020 & $\begin{array}{l}\text { NIMHANS, Bangalore, } \\
\text { Karnataka 560029,India }\end{array}$ \\
\hline 12 & QJF77844 & Muttineni,R., et al., 2020 & $\begin{array}{l}\text { VRL, Dept. of Zoology, } \\
\text { Osmania University, } \\
\text { Hyderabad-500007,India }\end{array}$ \\
\hline 13 & QJF77856 & Muttineni,R., et al., 2020 & $\begin{array}{l}\text { VRL, Dept. of Zoology, } \\
\text { Osmania University, } \\
\text { Hyderabad-500007,India }\end{array}$ \\
\hline 14 & QJF77868 & Muttineni,R., et al., 2020 & $\begin{array}{l}\text { VRL, Dept. of Zoology, } \\
\text { Osmania University, } \\
\text { Hyderabad-500007,India }\end{array}$ \\
\hline 15 & QJF77880 & Muttineni,R., et al., 2020 & $\begin{array}{l}\text { VRL, Dept. of Zoology, } \\
\text { Osmania University, } \\
\text { Hyderabad-500007,India }\end{array}$ \\
\hline 16 & QJQ27840 & Pattabiraman,C., et al., 2020 & $\begin{array}{l}\text { NIMHANS, Bangalore, } \\
\text { Karnataka 560029,India }\end{array}$ \\
\hline 17 & QJQ27852 & Pattabiraman,C., et al., 2020 & $\begin{array}{l}\text { NIMHANS, Bangalore, } \\
\text { Karnataka 560029,India }\end{array}$ \\
\hline 18 & QJQ27864 & Pattabiraman,C., et al., 2020 & $\begin{array}{l}\text { NIMHANS, Bangalore, } \\
\text { Karnataka 560029,India }\end{array}$ \\
\hline 19 & QJQ27876 & Pattabiraman,C., et al., 2020 & $\begin{array}{l}\text { NIMHANS, Bangalore, } \\
\text { Karnataka 560029,India }\end{array}$ \\
\hline 20 & QJQ28343 & Trivedi, P., et al., 2020 & $\begin{array}{l}\text { GBRC, Gandhinagar, } \\
\text { Gujarat 382011, India }\end{array}$ \\
\hline 21 & QJQ28355 & Hinsu, A., et al., 2020 & GBRC, Gandhinagar, \\
\hline
\end{tabular}




\begin{tabular}{|l|l|l|l|}
\hline 22 & QJQ28367 & Sabara, P., et al., 2020 & $\begin{array}{l}\text { Gujarat 382011, India } \\
\text { GBRC, Gandhinagar, } \\
\text { Gujarat 382011, India }\end{array}$ \\
\hline 23 & QJQ28379 & Puvar, A., et al., 2020 & $\begin{array}{l}\text { GBRC, Gandhinagar, } \\
\text { Gujarat 382011, India }\end{array}$ \\
\hline 24 & QJQ28391 & Raval, J., et al., 2020 & $\begin{array}{l}\text { GBRC, Gandhinagar, } \\
\text { Gujarat 382011, India }\end{array}$ \\
\hline 25 & QJQ28403 & Gandhi, M., et al., 2020 & $\begin{array}{l}\text { GBRC, Gandhinagar, } \\
\text { Gujarat 382011, India }\end{array}$ \\
\hline 26 & QJQ28415 & Shah, T., et al., 2020 & $\begin{array}{l}\text { GBRC, Gandhinagar, } \\
\text { Gujarat 382011, India }\end{array}$ \\
\hline 27 & QJQ28427 & Pandya, M., et al., 2020 & $\begin{array}{l}\text { GBRC, Gandhinagar, } \\
\text { Gujarat 382011, India }\end{array}$ \\
\hline
\end{tabular}

